\begin{tabular}{|l|l|}
\hline $\begin{array}{l}\text { Postprint } \\
\text { Version }\end{array}$ & 1.0 \\
\hline Journal website & $\underline{\text { http://link.springer.com/article/10.1007\%2Fs00520-012-1619-0 }}$ \\
\hline Pubmed link & $\underline{\text { http://www.ncbi.nlm.nih.gov/pubmed/23064901 }}$ \\
\hline DOI & $10.1007 /$ s00520-012-1619-0 \\
\hline
\end{tabular}

This is a NIVEL certified Post Print, more info at http://www.nivel.eu

\title{
Variation in medication use in cancer patients at the end of life: a cross-sectional analysis
}

\author{
N. J. H. RAIJMAKERS \& L. VAN ZUYLEN \& C. J. FURST \& M. BECCARO \& L. MAIORANA \& P. \\ PILASTRI \& C. ROSSI \& G. FLEGO \& A. VAN DER HEIDE \& M. COSTANTINI
}

\begin{abstract}
Purpose Despite advances in cancer treatment, patients still die with unnecessary suffering. Therefore, high-quality end of- life care is needed. Variations in medication use at the end of life may suggest areas for improvement. This study aims to describe the use of medications during the last days of life of cancer patients and to explore the possibility of using it as a quality measure.

Methods We conducted an international survey on experts' opinions regarding potentially inappropriate medications for dying patients. Subsequently, a chart review of deceased cancer patients was conducted, which assessed the current medication use in different settings.

Results The mean number of medications used in the last 3 days of life was 4.8 (SD 2.1). Hospital patients were less likely than hospice patients to receive opioids, midazolam, haloperidol, and drugs for pulmonary secretions or nausea/ vomiting. Over $90 \%$ of experts rated 12 medications as unlikely to be appropriate. Hospital patients were more likely than hospice patients to receive these potentially inappropriate medications. Before the implementation of an end-of-life care pathway, hospital patients had a higher probability, than after, to receive potentially inappropriate medication. Moreover, after implementation of such pathway, patients for whom a pathway was not used were more likely to receive potentially inappropriate medications than patients for whom it was used. Conclusion Medication use at the end of life varies widely by setting, both for potentially appropriate and inappropriate medications.

Combining experts' opinion and current medication use resulted in the identification of 16 medications that might be used to assess the quality of cancer care at the end of life.
\end{abstract}

\section{INTRODUCTION}

Despite advances in early detection, treatment, and survival of cancer, a large proportion of cancer patients still dies with unmet needs [1, 2]. Therefore, highquality care in the last days of life is important. Recognition of the dying phase is important for high-quality care, and it has been shown to be feasible in a large 
proportion of patients dying from cancer [3]. Hospital care frequently involves burdensome interventions, with patients experiencing unremitting pain and suffering in the final week of life [4]. Over the last decade, attention to end-oflife care in hospitals has increased, as reflected in the growth of palliative care services in hospitals, such as palliative care consultation teams, and the increasing use of care pathways for dying patients, such as the Liverpool Care Pathway for the Dying Patient [5]. Palliative care consultation teams in hospitals have been shown to have beneficial effects, such as better quality of life of patients [6-9] and less aggressive care, which is concordant with the patients' preferences at the end of life [7]. Furthermore, the use of the Liverpool Care Pathway for the Dying Patient (LCP) has been shown to lead to better symptom control, better bereavement outcomes, and a more comprehensive documentation of care [10], and has previously been considered as a measure of quality [11].

Quality indicators are essential in assessing, evaluating, and improving the quality of care, but finding appropriate quality indicators for end-of-life cancer care is challenging [12]. Measurement of quality indicators should be quick and efficient, so feedback can be provided on a regular basis. Data from medical records have been suggested as quality indicators before [13-15]. This includes medication prescription and use, which are already used as quality indicators in other fields [16-18] and have also been suggested as indicator in the field of palliative care [19]. Medication use should be in concordance with the goals of care and applicable guidelines. In the dying phase, medication use should be evaluated, non-essential medications should be withdrawn [20], and inappropriate medications should be avoided. Little is known about the current use of medications in the last days of life of cancer patients, although there are indications of unnecessary medication use among advance cancer patients [21] and of variation in pain medication use at the end of life [19]. Assessing patterns of medication use is the first step towards understanding medication use as a potential quality measure for end-of-life care. The aim of our study was to describe the use of potentially inappropriate and appropriate medications during the last days of life in cancer care and to explore whether medication use might be a potential quality indicator in end-of-life care.

\section{MATERIALS AND METHODS}

\section{Survey of international experts}

We conducted an explorative survey among international experts in palliative care to generate a list of potentially inappropriate medications in the care for dying cancer patients. Purposive sampling was used to construct an international expert panel; 20 palliative care physicians from ten different countries were contacted. The selection criteria used included being a physician and having expertise in the field of palliative care. The sample included palliative care physicians from Argentina (two), Germany (two), Italy (two), the Netherlands (two), New Zealand (two), Slovenia (two), Spain (two), Sweden (two), Switzerland (two), and the UK (two). After one reminder, 16 experts responded (response rate $80 \%$ ). Non-responders originated from Slovenia (two), Switzerland (one), and the UK (one). 
Raijmakers, N.J.H., Zuylen, L. van, Furst, C.J., Beccaro, M., Maiorana, L., Pilastri, P., Rossi, C. Flego, G., Heide, A. van der, Costantini, M. Variation in medication use in cancer patients at the end of life: a cross-sectional analysis. Supportive Care in Cancer: 2013, 21(4), 1003-1011

\section{Questionnaire}

To formulate the questionnaire of our survey, we conducted a literature search in the database PubMed to identify potentially inappropriate medications, using the search terms "inappropriate medication", "futile medication", "unnecessary medication", "palliative care", "end-of-life care", and "terminally ill". The final questionnaire assessed the experts' opinions on 20 potentially inappropriate medications in the last 3 days of life. The experts were asked to rate the medication's probability of being useful in cancer patients' last days of life.

A four-point Likert scale was used, with 1 for "low", 4 for "high", and a "don't know" option. The questionnaire focused on the last days of life because it is known that in the vast majority of cases, physicians are able to recognize when cancer patients are imminently dying [22]. Furthermore, the respondents were asked to add other potentially inappropriate medications. The experts' responses directed the medical chart review by guiding the selection of potentially inappropriate medications.

\section{Chart review}

This retrospective study was conducted to assess medication use during the last 3 days of life of cancer patients in a hospital or hospice. In total, we included 135 cancer patients (ICD-IX 140-239) who consecutively died in the General Medicine wards or the Respiratory Disease ward of the Villa Scassi Hospital of Genoa (Italy) between December 2006 and July 2009. Halfway through this period, the LCP was implemented in these departments. In addition, 60 consecutive deceased cancer patients who died between February and May 2011 in the Hospice Maria Chighine of Genoa were included. For each patient, demographics and information regarding medication use in the last 3 days of life were collected using a standard care assessment tool. This tool was developed for the assessment of the Italian version of the LCP [23, 24], and in this study, it was used to assess potentially inappropriate and appropriate medications. Potentially inappropriate medications included all medications rated by the experts as being "unlikely to be appropriate" (Appendix). All supplements were merged into one category, and two additional medications were added: vasodilator drugs and dopamine. The appropriate medications were derived from the textbook Care for the Dying [5]. Furthermore, data about routes of administration, except creams, eye drops, and topical mouth drugs (e.g. antimicotics), were collected.

Double assessment (MC and PP) of a random subsample was performed to guarantee the quality of the data collection.

Discrepancies were discussed and verified in the medical charts. These assessments suggested good reliability of the data; the maximal number of discrepancies per item was $7 \%$, and $97 \%$ of all items had a kappa of $>0.6$.

\section{Statistical analyses}

The medications that were scored by at least $90 \%$ of the experts as having a low likelihood of being useful (score 1 or 2) were classified as being "unlikely to be appropriate".

This classification was used to indicate variances in medication use in cancer patients who died in different settings.

These settings had an expected difference in the quality of care. We conducted three analyses. First, we compared medication use of patients in the hospital (before LCP 
implementation) with patients in the hospice, under the assumption that hospice care is of better quality [25, 26].

Second, patients dying before and after implementation of the LCP program in the hospital were compared [10, 24].

We assumed that this program improved the quality of end of- life care. Third, after the implementation of the LCP in the hospital, patients for whom the LCP was used were compared with patients for whom the LCP was not used.

We assumed that dying when on the LCP involves better quality of end-of-life care [10].

To compare groups, bivariate crude odds ratios with $95 \%$ confidence interval (CI) were calculated. Medication classes with at least two odds ratios (ORs) in the expected direction were classified as potential quality indicators. For statistical analyses, we used SPSS (SPSS PASW 17 17.0.2 ENG, Win Wrap Basic, Polar Engineering and Consulting).

\section{Ethical consideration}

The project protocol was approved by the Ethical Committee of the National Cancer Institute of Genoa and of the Villa Scassi Hospital.

\section{RESULTS}

\section{The survey of international experts}

All experts rated supplements (iron, vitamin, and other), bisphosphonates, replacement hormones, hyperuricemia drugs, and anticoagulants as being unlikely to be appropriate in the last days of life of cancer patients (Appendix).

Medications rated as being unlikely to be appropriate by $94 \%$ of all experts were antihypertensives, antiarrhythmics, antiulcer drugs, antibiotics, and steroids. Overall, 12 classes of medication were classified as being potentially inappropriate by the experts.

\section{The medical chart review}

Of the 195 patients included in the medical chart review, 38 \% were female (Table 1). The mean age was 74 and 72 years for hospital and hospice patients, respectively. The most common primary tumors were respiratory, digestive, and genital/urinary tumors. The median length of admission was 9 days in the hospital and 10 days in the hospice. No significant differences in patient characteristics and length of admission were found. In the hospital, patients died significantly more often form respiratory cancers $(\mathrm{p}<0.001)$.

\section{Characteristics of medication use}

Patients received, on average, $4.8 \pm 2.1$ classes of medication in the last 3 days of life: 5.1 in the hospital and 4.7 in the hospice (Table 2). For patients in the hospice, medication was administered subcutaneously in $56 \%$ of all admission days. In the hospital, medication was administered subcutaneously only in $13 \%$ of all admission days, and in $80 \%$ of all admission days, other routes were used for administering medication.

\section{Variation in use of potentially inappropriate medication}

The proportion of patients in the hospital receiving medications that are likely to be inappropriate during the last 3 days of life was compared with the proportion of 
patients in the hospice (Table 3). In both settings, steroids and antiulcer drugs were the most often used potentially inappropriate medication types. Hospital patients had a significantly higher probability of receiving antiulcer drugs (OR 3.5; CI 1.7-7.1), antibiotics (OR 3.1; CI 1.4-6.9), vasodilator drugs (OR 4.9; CI 1.3-17.9), and dopamine (OR>8.4) compared to hospice patients. In the hospital, before and after the implementation of the LCP (Table 4), steroids and antiulcer drugs were the most often used potentially inappropriate types of medication. Patients who died before the implementation of LCP had a significantly higher probability of receiving vasodilator drugs (OR 3.8; CI 1.2-12.0) and a lower probability of receiving replacement hormones (OR 0.3; CI 0.1-0.8) than patients who died after LCP implementation. When comparing post-implementation hospital patients for whom LCP was actually used to those for whom the LCP was not used, patients dying without being on the LCP had a significantly higher probability of receiving antiulcer drugs (OR 5.8; CI 1.9-17.9), anticoagulants (OR 4.2; CI 1.1-16.4), replacement hormones (OR 7.3; CI 1.5-35.7), and dopamine (OR>2.6) (Table 5).

\section{[TABLE 1] [TABLE 2] [TABLE 3]}

Variation in the use of appropriate medication Table 3 shows the proportion of patients who received medications that are likely to be appropriate in the last 3 days of life in the hospital and hospice settings. In both settings, opioids and morphine were most often used. Hospital patients had a significantly lower probability of receiving appropriate medications than hospice patients; odds ratios ranged from 0.01 to 0.24 . Comparing hospital care before and after LCP implementation (Table 4), we found a significantly lower probability of receiving haloperidol (OR 0.5; CI 0.2-0.9),midazolam (OR 0.02; CI 0.003-0.2), medication for pulmonary secretions (OR 0.1; CI 0.04-0.3), and medication for nausea/vomiting (OR 0.2; CI 0.1-0.9) for patients before LCP implementation. Furthermore, we found a significantly lower probability of receiving appropriate medications, except medication for nausea or vomiting, for patients dying without being on the LCP compared to patients for whom LCP was used (Table 5).

\section{Medications as potential quality indicators}

Ten potentially inappropriate medications had at least two odds ratios in the expected direction: antiulcer drugs, antibiotics, anticoagulants, replacement hormones, antiarrhythmics, antihypertensives, vasodilator drugs, steroids, dopamine, and bisphosphonates. All six potentially appropriate medications had at least two odds ratios in the expected direction.

\section{DISCUSSION}

Medication use in the last days of cancer patients varies per setting for potentially appropriate and inappropriate classes of medication. Combining experts' opinions on the appropriateness of medications in the last days of life with current medication use in 195 patients in three different care settings resulted in 16 potential quality indicators for end-of-life care of the dying patient; ten medication types are potentially inappropriate, and six are likely to be appropriate drugs. These 16 potential quality measures need further exploration and validation. 
Data on inappropriate medication use have already been used as quality indicator in other fields of medicine. For example, the Beers criteria are well known and widely used to evaluate care for elderly patients [27, 28]. These criteria aim to identify inappropriate medication use in older adults, and the criteria enable care providers to plan interventions for minimizing drug-related problems, such as unnecessary polypharmacy or adverse drug events. In end-of-life care, there is also a growing interest in potential indicators for inappropriate care like aggressive end-of-life care, e.g., chemotherapy close to death [29, 30] and futile medication use among people with limited life expectancy [20, 31, 32].

Recently, variation in pain medication use at the end of life has been identified as potential quality measures [19]. One fifth of ambulatory advanced cancer patients use futile medications, and the prevalence of inappropriate medication use among patients with a limited life expectancy varies from 25 to $44 \%$ [20]. Subsequently, Maddison et al. [20] emphasize in their systematic review the need to develop a framework to assess inappropriate medication at the end of life.

\section{[TABLE 4]}

There are some concerns regarding using standard medical file data on medication use for quality assessment.

Especially, the lack of completeness and accuracy of such data are mentioned [14]. However, electronic patient records and electronic prescribing systems are increasingly present, which contribute to a higher quality of administrative data on medication use [33]. An increasing interest in medication safety and mandatory reporting of medication use will further improve the quality and reliability of medication data.

In this study, we used a well-developed and evaluated care assessment tool to ensure standardization of the data collection, and a double assessment of a random subsample was performed, which confirmed the reliability of this assessment tool. Furthermore, restricting the data collection period, i.e., the last 3 days of life, improved the feasibility, which is also an important feature of quality indicators. When using medication use as a quality indicator, it is important to realize that it aims at assessing the quality of care at an aggregate population level. Populationbased indicators for quality of end-of-life care are not designed to measure quality of care on the individual level. Individual patients may sometimes experience better quality of care due to the use of medications such as supplements, although these supplements are, in general, inappropriate in the last days of life.

We used an international expert panel to assess the appropriateness of medications. For constructing this panel, we used purposive sampling to ensure a panel with sufficient expertise in care for the dying. This may have led to selection bias because it is not a random sample. Therefore, the panel might not represent palliative care experts in general, which, however, does not significantly compromise the explorative aim of this research. Furthermore, we used consecutive samples of deceased cancer patients, which include all patients in the given time periods. Although it is a non-probability sampling method, for which it may not be assumed that the sample fully represents the target, consecutive sampling is a good choice within the non-probability sampling methods. However, some subgroups were small, e.g., deceased hospital patients for whom the LCP was used (n023). These small 
subgroups might endanger the comparability of patients who were on LCP and those who were not through possible imbalances in primary cancer sites. Patients for whom the LCP was used were relatively often diagnosed with respiratory cancer, which might explain the frequent use of medication for pulmonary secretions in this group.

\section{[TABLE 5]}

This study is a first step towards using data on medication use as a quality indicator in end-of-life care. Future studies are needed to validate these potentially inappropriate and appropriate medications as quality indicators. The association between the prevalence of their use and quality of cancer care should be assessed to verify construct validity. Finally, it is important to evaluate these potential quality indicators further to assess their feasibility, validity, and sensitivity. Our list of 16 medications may not be comprehensive. Lipid-lowering drugs, such as statins, are often mentioned as being inappropriate at the end of life. However, recognition of a life-limiting condition is not associated with less use of statins [31], and this lack of sensitivity implies statins to be a less useful quality indicator.

Although an increasing awareness of potentially inappropriate medical care in the last days of life is present, critical assessment of the appropriateness of care and medication during the last days of life still needs to disseminate further among professionals. End-of-life pathways, such as the LCP, urge professionals to evaluate potentially inappropriate medications; a prerequisite is recognition of the dying phase. Using end-of-life pathways may support professionals in recognizing the dying phase, increase awareness among professionals, and create an opportunity to discuss the situation with the patient and family. By these means, it might contribute to the improvement of end-of-life care.

In conclusion, medication use in the last days of life of cancer patients varies per setting. In total, 16 classes of medication with the potential to assess the quality of end-oflife cancer care were identified by combining experts' opinions on appropriateness of medications in the last days of life with a medical chart review of current medication use.

The use of these medications, single or combined, as quality indicators may contribute to better end-of-life cancer care and needs further exploration.

\section{ACKNOWLEDGMENTS}

This work was supported by the grant from the Italian Minister of Health (Progetto di Ricerca Finalizzata- RFPS-2006-6-341619) and from the Maruzza Lefebvre D'Ovidio Foundation-Onlus, Rome. The sponsors played no role in the conduct of the study, the analysis, as in the preparation of this manuscript.

\section{[TABLE 6]}

\section{REFERENCES}

1. Ferlay J, Parkin DM, Steliarova-Foucher E (2010) Estimates of cancer incidence and mortality in Europe in 2008. Eur J Cancer 46:765-781 
Raijmakers, N.J.H., Zuylen, L. van, Furst, C.J., Beccaro, M., Maiorana, L., Pilastri, P., Rossi, C Flego, G., Heide, A. van der, Costantini, M. Variation in medication use in cancer patients at the end of life: a cross-sectional analysis. Supportive Care in Cancer: 2013, 21(4), 1003-1011

2. Seow H, Barbera L, Sutradhar R, Howell D, Dudgeon D, Atzema C, Liu Y, Husain A, Sussman J, Earle C (2011) Trajectory of performance status and symptom scores for patients with cancer during the last six months of life. J Clin Oncol 29:1151-1158

3. Aabom B, Kragstrup J, Vondeling H, Bakketeig LS, Stovring H (2005) Defining cancer patients as being in the terminal phase: who receives a formal diagnosis, and what are the effects? J Clin Oncol 23:7411-7416

4. Connors FA Jr et al (1995) A controlled trial to improve care for seriously ill hospitalized patients. The study to understand prognoses and preferences for outcomes and risks of treatments (SUPPORT). The SUPPORT Principal Investigators. JAMA 274:1591-1598

5. Ellershaw J, Wilkinson S (2011) Care for the dying: a pathway to excellence. University Press, Oxford

6. Bakitas M, Lyons KD, Hegel MT, Balan S, Brokaw FC, Seville J, Hull JG, Li Z, Tosteson TD, Byock IR, Ahles TA (2009) Effects of a palliative care intervention on clinical outcomes in patients with advanced cancer: the Project ENABLE II randomized controlled trial. JAMA 302:741-749

7. Temel JS, Greer JA, Muzikansky A, Gallagher ER, Admane S, Jackson VA, Dahlin CM, Blinderman CD, Jacobsen J, Pirl WF, Billings JA, Lynch TJ (2010) Early palliative care for patients with metastatic non-small-cell lung cancer. N Engl J Med 363:733-742

8. Gelfman LP, Meier DE, Morrison RS (2008) Does palliative care improve quality? A survey of bereaved family members. J Pain Symptom Manage 36:22-28

9. Higginson IJ, Finlay I, Goodwin DM, Cook AM, Hood K, Edwards AG, Douglas HR, Norman CE (2002) Do hospitalbased palliative teams improve care for patients or families at the end of life? J Pain Symptom Manage 23:96-106

10. Veerbeek L, van Zuylen L, Swart SJ, van der Maas PJ, de Vogel- Voogt E, van der Rijt CC, van der Heide A (2008) The effect of the Liverpool Care Pathway for the dying: a multicentre study. Palliat Med 22:145-151

11. Pugh EJ, McEvoy M, Blenkinsopp J (2010) Use of the proportion of patients dying on an end of life pathway as a quality marker: considerations for interpretation. Palliat Med 24:544-547

12. Raijmakers N, Galushko M, Domeisen F, Beccaro M, Lundh Hagelin C, Lindqvist $O$, Popa-Velea O, Romotzky V, Schuler S, Ellershaw J, Ostgathe C, On Behalf Of Opcare C (2012) Quality indicators for care of cancer patients in their last days of life: literature update and experts' evaluation. J Palliat Med 15:308-316

13. Iezzoni LI (1997) Assessing quality using administrative data. Ann Intern Med 127:666674

14. Earle CC, Park ER, Lai B, Weeks JC, Ayanian JZ, Block S (2003) Identifying potential indicators of the quality of end-of-life cancer care from administrative data. $\mathrm{J}$ Clin Oncol 21:1133-1138

15. Grunfeld E, Lethbridge L, Dewar R, Lawson B, Paszat LF, Johnston G, Burge F, McIntyre P, Earle CC (2006) Towards using administrative databases to measure population-based indicators of quality of end-of-life care: testing the methodology. Palliat Med 20:769-777

16. Katz A, Soodeen RA, Bogdanovic B, De Coster C, Chateau D (2006) Can the quality of care in family practice be measured using administrative data? Health Serv Res 41:22382254

17. Saag KG, Olivieri JJ, Patino F, Mikuls TR, Allison JJ, MacLean CH (2004) Measuring quality in arthritis care: the Arthritis Foundation's quality indicator set for analgesics. Arthritis Rheum 51:337-349

18. Winslade N, Taylor L, Shi S, Schuwirth L, Van der Vleuten C, Tamblyn R (2011) Monitoring community pharmacist's quality of care: a feasibility study of using pharmacy claims data to assess performance. BMC Health Serv Res 11:12

19. Zerzan J, Benton K, Linnebur S, O'Bryant C, Kutner J (2010) Variation in pain medication use in end-of-life care. J Palliat Med 13:501-504

20. Maddison AR, Fisher J, Johnston G (2011) Preventive medication use among persons with limited life expectancy. Prog Palliat Care 19:15-21

21. Fede A, Miranda M, Antonangelo D, Trevizan L, Schaffhausser H, Hamermesz B, Zimmermann C, Del Giglio A, Riechelmann RP (2011) Use of unnecessary medications by 
Raijmakers, N.J.H., Zuylen, L. van, Furst, C.J., Beccaro, M., Maiorana, L., Pilastri, P., Rossi, C Flego, G., Heide, A. van der, Costantini, M. Variation in medication use in cancer patients at the end of life: a cross-sectional analysis. Supportive Care in Cancer: 2013, 21(4), 1003-1011

patients with advanced cancer: cross-sectional survey. Support Care Cancer 19:13131318

22. Sullivan AM, Lakoma MD, Matsuyama RK, Rosenblatt L, Arnold RM, Block SD (2007) Diagnosing and discussing imminent death in the hospital: a secondary analysis of physician interviews. J Palliat Med 10:882-893

23. Costantini MDLS, Beccaro M (2011) Methodological issues in a before-after study design to evaluate the Liverpool Care Pathway for the Dying Patient in hospital. Palliat Med Dec 25(8):766-773

24. Costantini M, Ottonelli S, Canavacci L, Pellegrini F, Beccaro M, Group LCPRICTS (2011) The effectiveness of the Liverpool care pathway in improving end of life care for dying cancer patients in hospital. A cluster randomised trial. BMC Health Serv Res 11:13

25. Shuman AG, Yang Y, Taylor JM, Prince ME (2011) End-of-life care among head and neck cancer patients. Otolaryngol Head Neck Surg 144:733-739

26. Gomes B, McCrone P, Hall S, Koffman J, Higginson IJ (2010) Variations in the quality and costs of end-of-life care, preferences and palliative outcomes for cancer patients by place of death: the QUALYCARE study. BMC Cancer 10:400

27. Beers MH (1997) Explicit criteria for determining potentially inappropriate medication use by the elderly. An update Arch Intern Med 157:1531-1536

28. Fick DM, Cooper JW,WadeWE,Waller JL, Maclean JR, Beers MH (2003) Updating the Beers criteria for potentially inappropriate medication use in older adults: results of a US consensus panel of experts.

Arch Intern Med 163:2716-2724

29. Ho TH, Barbera L, Saskin R, Lu H, Neville BA, Earle CC (2011) Trends in the aggressiveness of end-of-life cancer care in the universal health care system of Ontario, Canada. J Clin Oncol 29:1587-1591

30. Nappa U, Lindqvist O, Rasmussen BH, Axelsson B (2011) Palliative chemotherapy during the last month of life. Ann Oncol: Off J Eur Soc Med Oncol/ESMO 22:2375-2380

31. Silveira MJ, Kazanis AS, Shevrin MP (2008) Statins in the last six months of life: a recognizable, life-limiting condition does not decrease their use. J Palliat Med 11:685-693

32. Riechelmann RP, Krzyzanowska MK, Zimmermann C (2009) Futile medication use in terminally ill cancer patients. Support Care Cancer 17:745-748

33. Appari A, Carian EK, Johnson ME, Anthony DL (2011) Medication administration quality and health information technology: a national study of US hospitals. J Am Med Inform Assoc 
Raijmakers, N.J.H., Zuylen, L. van, Furst, C.J., Beccaro, M., Maiorana, L., Pilastri, P., Rossi, C, Flego, G., Heide, A. van der, Costantini, M. Variation in medication use in cancer patients at the end of life: a cross-sectional analysis. Supportive Care in Cancer: 2013, 21(4), 1003-1011

\section{TABLES AND FIGURES}

Table 1 Characteristics of deceased cancer patients

\begin{tabular}{|c|c|c|c|c|c|}
\hline & \multirow{2}{*}{$\begin{array}{l}\text { Hospice } \\
\text { All } \\
N=60\end{array}$} & \multicolumn{4}{|l|}{ Hospital } \\
\hline & & $\begin{array}{l}\text { Pre-LCPa } \\
N=73\end{array}$ & $\begin{array}{l}\text { Post-LCP } \\
N=62\end{array}$ & $\begin{array}{l}\text { No LCP } \\
N=39\end{array}$ & $\begin{array}{l}\text { On LCP } \\
N=23\end{array}$ \\
\hline Female & $23(38)$ & $23(32)$ & $28(45)$ & $19(49)$ & $9(39)$ \\
\hline Age (mean(SD)) & $72(14)$ & $76(10)$ & $73(11)$ & $74(11)$ & $72(10)$ \\
\hline \multicolumn{6}{|l|}{ Primary cancer site } \\
\hline Digestive & $26(43)$ & $16(22)$ & $8(13)$ & $7(18)$ & $1(4)$ \\
\hline Respiratory & $12(20)$ & $33(45)$ & $30(48)$ & $15(39)$ & $15(65)$ \\
\hline Genital urinary & $14(23)$ & $10(14)$ & $4(7)$ & $3(8)$ & $1(4)$ \\
\hline Hematological & $2(3)$ & $8(11)$ & $6(10)$ & $4(10)$ & $2(9)$ \\
\hline Other & $6(10)$ & $6(8)$ & $14(23)$ & $10(26)$ & $4(17)$ \\
\hline Days in the ward (median, (lower-upper quartiles)) & $10(3-19)$ & $8(3-15)$ & $11(4-20)$ & $9(4-20)$ & $14(3-22)$ \\
\hline
\end{tabular}

All figures represent numbers and percentages unless otherwise specified

"LCP is the Liverpool Care Pathway for the Dying Patient. Pre- and post-LCP include all cancer deaths that occurred in the participating wards in the 4 months before and after the implementation of LCP, respectively

'No LCP includes all cancer deaths that occurred in the hospital for which the LCP was not used after the implementation of LCP. On LCP includes all cancer deaths that occurred in the wards for which the LCP was used

Table 2 Other characteristics of medication use in patients in their last 3 days of life

\begin{tabular}{|c|c|c|c|c|c|}
\hline & \multirow{2}{*}{$\begin{array}{l}\text { Hospice } \\
\text { All } \\
N=60\end{array}$} & \multicolumn{4}{|l|}{ Hospital } \\
\hline & & $\begin{array}{l}\text { Pre-LCP } \\
N=73\end{array}$ & $\begin{array}{l}\text { Post-LCP } \\
N=62\end{array}$ & $\begin{array}{l}\text { No LCP } \\
N=39\end{array}$ & $\begin{array}{l}\text { On LCP } \\
N=23\end{array}$ \\
\hline \multicolumn{6}{|l|}{ Poly-medication use (mean (SD)) } \\
\hline Number of medications & $4.7(1.8)$ & $5.3(24)$ & $4.9(2.0)$ & $5.2(2.1)$ & $4.5(1.7)$ \\
\hline Route of administration (\%) & $N=165$ days & $N=202$ days & $N=180$ days & $N=112$ days & $N=68$ days \\
\hline Days with no medication & $2(3)$ & $6(12)$ & $9(16)$ & $14(16)$ & $0(0)$ \\
\hline Days with only subcutaneous & $56(92)$ & $4(9)$ & $22(39)$ & $6(7)$ & $47(32)$ \\
\hline Days with other routes & $42(70)$ & $90(181)$ & $69(125)$ & $79(89)$ & $53(36)$ \\
\hline
\end{tabular}

All are numbers and percentages unless indicated otherwise

${ }^{\text {a } L C P}$ is the Liverpool Care Pathway for the Dying Patient. Pre- and post-LCP include all cancer deaths that occurred in the participating wards in the 4 months before and after the implementation of LCP, respectively

${ }^{b}$ No LCP includes all cancer deaths that occurred in the hospital for which the LCP was not used after the implementation of LCP. On LCP includes all cancer deaths that occurred in the wards for which the LCP was used 
Raijmakers, N.J.H., Zuylen, L. van, Furst, C.J., Beccaro, M., Maiorana, L., Pilastri, P., Rossi, C, Flego, G., Heide, A. van der, Costantini, M. Variation in medication use in cancer patients at the end of life: a cross-sectional analysis. Supportive Care in Cancer: 2013, 21(4), 1003-1011

Table 3 Patients receiving potentially inappropriate and appropriate medication in last 3 days of life; hospital vs. hospice

\begin{tabular}{|c|c|c|c|c|}
\hline \multirow[b]{2}{*}{ Potentially inappropriate medication ${ }^{b}$} & \multirow{2}{*}{$\begin{array}{l}\text { Hospital pre-LCP } \\
N=73 \\
\%(N)\end{array}$} & \multirow{2}{*}{$\begin{array}{l}\text { Hospice } \\
N=60 \\
\%(N)\end{array}$} & \multicolumn{2}{|c|}{ Hospital vs hospice (ref) } \\
\hline & & & OR & $95 \% \mathrm{CI}$ \\
\hline Supplements & $16(12)$ & - & $>11.8^{e}$ & - \\
\hline Replacements hormones & $11(8)$ & $3(2)$ & 3.6 & $0.7-17.5$ \\
\hline Bisphosphonates & $3(2)$ & - & $>1.7^{c}$ & - \\
\hline Hyperuricemia drugs & - & - & - & - \\
\hline Anticoagulants & $26(19)$ & $23(14)$ & 1.2 & $0.5-2.6$ \\
\hline Antihypertensive & $15(11)$ & $5(3)$ & 3.4 & $0.9-12.7$ \\
\hline Antiarnyythmics & $21(15)$ & $8(5)$ & 2.8 & $1.0-8.4$ \\
\hline Antiulcer drugs & $70(51)$ & $40(24)$ & 3.5 & $1.7-7.1$ \\
\hline Antibiotics & $41(30)$ & $18(11)$ & 3.1 & $1.4-6.9$ \\
\hline Steroids & $69(50)$ & $72(43)$ & 0.9 & $0.4-1.8$ \\
\hline Vasodilator drugs & $21(15)$ & $5(3)$ & 4.9 & $1.3-17.9$ \\
\hline Dopamine & $12(9)$ & - & $>8.4^{\mathrm{e}}$ & - \\
\hline \multicolumn{5}{|l|}{ Appropriate medication } \\
\hline Opioids & $81(59)$ & $95(57)$ & 0.22 & $0.06-0.8$ \\
\hline Morphine & $64(47)$ & $93(56)$ & 0.13 & $0.04-0.4$ \\
\hline Midazolam & $1(1)$ & $50(30)$ & 0.01 & $0.002-0.1$ \\
\hline Haloperidol & $25(18)$ & $75(45)$ & 0.11 & $0.05-0.2$ \\
\hline For pulmonary secretions & $7(5)$ & $68(41)$ & 0.03 & $0.01-0.1$ \\
\hline For nausea/vomiting ${ }^{d}$ & $4(3)$ & $15(9)$ & 0.24 & $0.06-0.9$ \\
\hline
\end{tabular}

Italic $O R$ indicate significant values, $p<0,05$

${ }^{a}$ LCP is the Liverpool Care Pathway for the Dying Patient. Pre-LCP includes all cancer deaths that occurred in the participating wards in the 4 months before the implementation of LCP

${ }^{b} \mathrm{Classes}$ of inappropriate medications are ordered by the likelihood of being inappropriate in the last 3 days of life, as rated by the palliative care experts

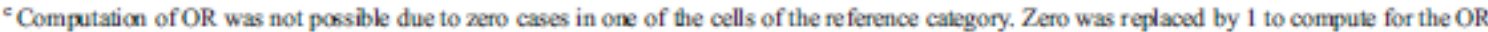

${ }^{\mathrm{d}}$ Medication for nausea and vomiting includes metoclopramide and levomepromazine 
Raijmakers, N.J.H., Zuylen, L. van, Furst, C.J., Beccaro, M., Maiorana, L., Pilastri, P., Rossi, C, Flego, G., Heide, A. van der, Costantini, M. Variation in medication use in cancer patients at the Ve end of life: a cross-sectional analysis. Supportive Care in Cancer: 2013, 21(4), 1003-1011

Table 4 Patients receiving potentially inappropriate and appropriate medication in the last 3 days of life; hospital pre-LCP vs. hospital post-LCP

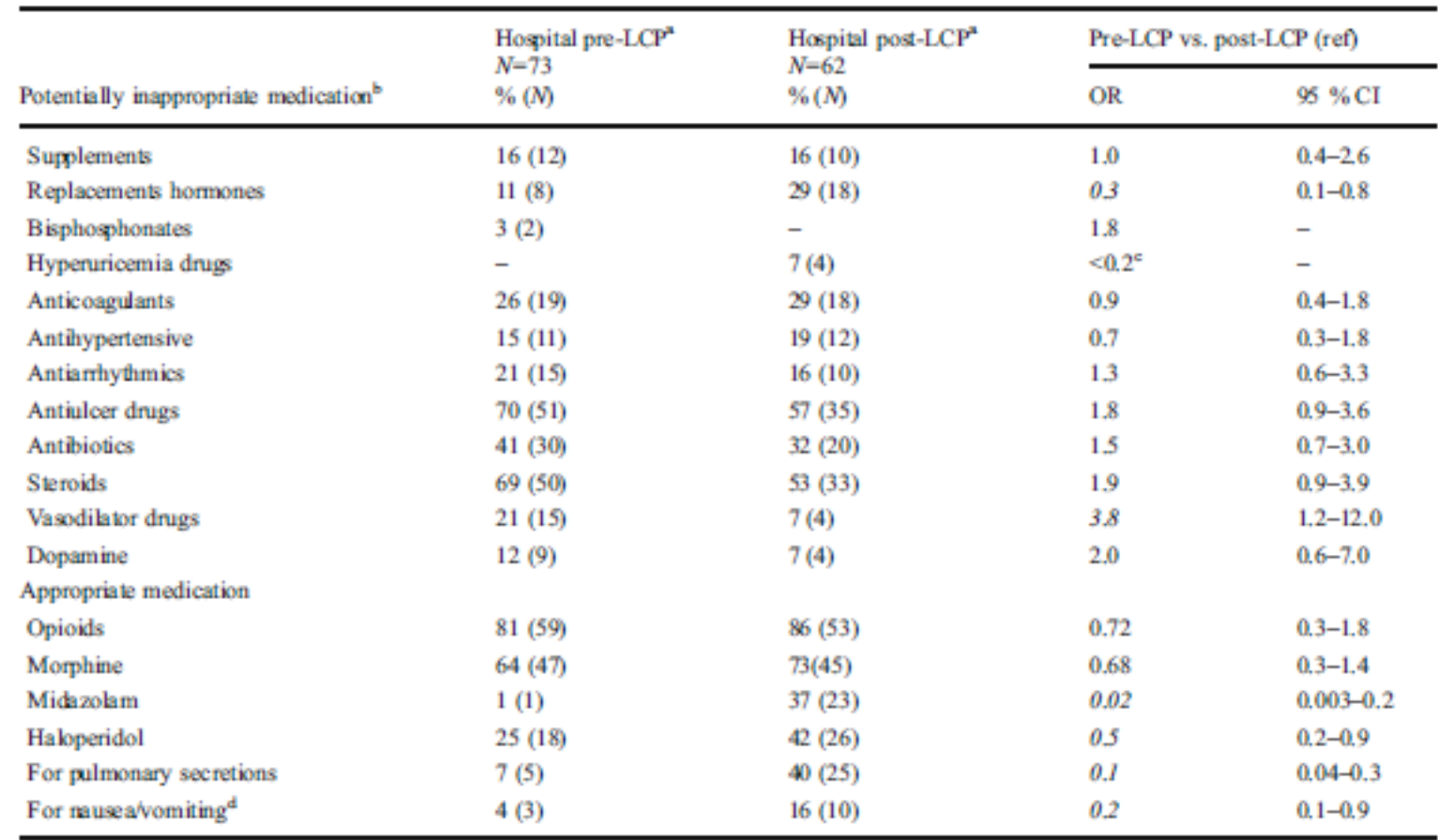

Italic OR indicate signficiant values, $p<0.05$

${ }^{\text {"}}$ LCP is the Liverpool Care Pathway for the Dying Patient. Pre- and post-LCP include all cancer deaths that occurred in the participating wards in the 4 months before and after the implementation of LCP, respectively

${ }^{b} \mathrm{Classes}$ of inappropriate medications are ordered by the likelihood of be ing inappropriate in the last 3 days of life, as rated by the palliative care experts

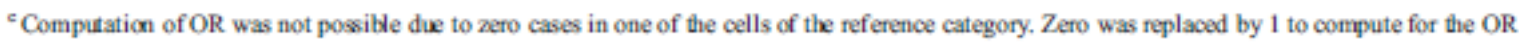

${ }^{\mathrm{d}}$ Medication for nausea and vomiting includes metoclopramide and levomepromazine 
Raijmakers, N.J.H., Zuylen, L. van, Furst, C.J., Beccaro, M., Maiorana, L., Pilastri, P., Rossi, C, Flego, G., Heide, A. van der, Costantini, M. Variation in medication use in cancer patients at the Ve end of life: a cross-sectional analysis. Supportive Care in Cancer: 2013, 21(4), 1003-1011

Table 5 Patients receiving potentially inappropriate and appropriate medication in last 3 days of life; hospital no LCP vs. hospital on LCP

\begin{tabular}{|c|c|c|c|c|}
\hline \multirow[b]{2}{*}{ Potentially inappropriate medication ${ }^{b}$} & \multirow{2}{*}{$\begin{array}{l}\text { Hospital no LCP } \\
N=39 \\
\%(N)\end{array}$} & \multirow{2}{*}{$\begin{array}{l}\text { Hospital on LCP" } \\
N=23 \\
\%(N)\end{array}$} & \multicolumn{2}{|c|}{ No LCP vs on LCP (ref) } \\
\hline & & & OR & $95 \% \mathrm{CI}$ \\
\hline Supplements & $23(9)$ & $4(1)$ & $6.6^{\mathrm{c}}$ & $0.8-55.6$ \\
\hline Replacements hormones & $41(16)$ & $9(2)$ & 7.3 & $1.5-35.7$ \\
\hline Bisphoophonates & - & - & - & - \\
\hline Hyperuricemia drugs & $8(3)$ & $4(1)$ & 1.8 & $0.2-18.9$ \\
\hline Anticoagulants & $39(15)$ & $13(3)$ & 4.2 & $1.1-16.4$ \\
\hline Antihypertensive & $28(11)$ & $4(1)$ & 8.6 & $1.0-71.4$ \\
\hline Antiarnhythmics & $13(5)$ & $22(5)$ & 0.5 & $0.1-12.2$ \\
\hline Antiulcer drugs & $72(28)$ & $30(7)$ & 5.8 & $1.9-17.9$ \\
\hline Antibiotics & $41(16)$ & $17(4)$ & 3.3 & $0.9-11.6$ \\
\hline Steroids & $56(22)$ & $48(11)$ & 1.4 & $0.5-4.0$ \\
\hline Vasodilator dnugs & $8(3)$ & $4(1)$ & 1.8 & $0.2-18.9$ \\
\hline Dopamine & $10(4)$ & - & $>2.6^{\mathrm{e}}$ & - \\
\hline \multicolumn{5}{|l|}{ Appropriate medication } \\
\hline Opioids & $77(30)$ & $100(23)$ & $<0.14^{c}$ & - \\
\hline Morphine & $62(24)$ & $91(21)$ & 0.15 & $0.03-0.7$ \\
\hline Midazolam & $13(5)$ & $78(18)$ & 0.04 & $0.01-0.2$ \\
\hline Haloperidol & 28 (11) & $65(15)$ & 0.2 & $0.07-0.6$ \\
\hline For pulmonary secretions & $15(6)$ & 83 (19) & 0.04 & $0.01-0.2$ \\
\hline For nausea/vomiting ${ }^{d}$ & $21(8)$ & $9(2)$ & 2.7 & $0.5-14.1$ \\
\hline
\end{tabular}

Italic OR indicate signficiant values, $p<0.05$

${ }^{2}$ LCP is the Liverpool Care Pathway for the Dying Patient. No LCP includes all cancer dea ths that occurred in the hospital for which the LCP was not used after the implementation of LCP. On LCP includes all cancer deaths that occurned in the wards for which the LCP was used

${ }^{b} \mathrm{Classes}$ of inappropriate medications are ordered by the likelihood of be ing inappropriale in the last 3 days of life, as rated by the palliative care experts

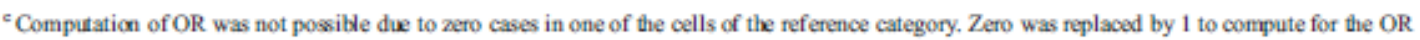

${ }^{\mathrm{d}}$ Medication for nausea and vomiting includes metoclopramide and levomepromazine 
Raijmakers, N.J.H., Zuylen, L. van, Furst, C.J., Beccaro, M., Maiorana, L., Pilastri, P., Rossi, C, Flego, G., Heide, A. van der, Costantini, M. Variation in medication use in cancer patients at the IVe end of life: a cross-sectional analysis. Supportive Care in Cancer: 2013, 21(4), 1003-1011

Table 6 Percentage of experts $(N=16)$ indicating potential inappropriateness of medication in last three days of life

Potentially inappropriate medication

Low likelihood of being appropriate ${ }^{*}(\%)$

Likely inappropriate medication

Iron supplements

100

Vitamin supplements

100

Replacements hormones

100

Bisphosponates

100

Other supplements

100

Hypenuricemia drugs $\quad 100$

Anticoagulants $\quad 100$

Antïhypertensive $\quad 94$

Antiarrhythmics 94

Antiulcer dngs $\quad 94$

Antibiotics 94

Steroids 94

Appropriateness unclear

Laxatives $\quad 81$

Antidepressants $\quad 81$

Pulmonary drugs $\quad 81$

Hypoglycemics $\quad 81$

Diuretics 56

NSAIDs $\quad 56$

Anticonvukants $\quad 38$

Benzodizzepines $\quad 20$

${ }^{\text {a }}$ Scored as $1 \propto 2$ on a 4-point Likert scale from bw (1) to high(4) likelihood of being appropriate in the last three days of life 